\title{
POLÍTICAS PÚBLICAS EDUCACIONAIS E O USO DAS TECNOLOGIAS NO ATENDIMENTO EDUCACIONAL ESPECIALIZADO
}

\section{PUBLIC POLICY EDUCATIONAL AND USE OF TECHNOLOGIES IN SPECIALIST EDUCATIONAL SERVICE}

\begin{abstract}
Aline Dal Bem Venturini - PPGTER/ UFSM- alinedalbem84@hotmail.com Liziany Müller Medeiros- PPGTER/ UFSM- lizianym@ hotmail.com
\end{abstract}

RESUMO: Busca-se a partir de um ensaio teórico exploratório evidenciar a presença das novas Tecnologias, mediante o aporte teórico de políticas públicas, que fomentam e problematizam a necessidade destas dentro das escolas, em vista de analisar seu uso no avanço da inclusão e adaptação dos alunos com deficiência. No limiar desta discussão, o papel do educador frente ao uso dos aparatos tecnológicos em sala de aula precisa ser problematizado, pois, a este profissional é necessário fornecer formação adequada às novas tecnologias. A partir disso, enfoca-se na problematização e reflexão acerca da inclusão digital em sala de aula.

Palavras-Chave: Tecnologias. Inclusão. Políticas Públicas. Educação.

\begin{abstract}
Search up from an exploratory theoretical test show the presence of new technologies by the theoretical framework of public policies that promote and question the need for these in schools, in order to analyze its use in the advancement of inclusion and adaptation of students with disabilities. On the threshold of this discussion, the role of the educator against the use of technological devices in the classroom needs to be questioned, because this professional is necessary to provide proper training to new technologies. From this, it focuses on the questioning and reflection on digital inclusion classroom.
\end{abstract}

Keywords: Technologies. Inclusion. Public policy. Education.

\section{INTRODUÇÃO}

Compreender as transformações no século XXI é pensar nas concepções e rumos que o desenvolvimento econômico, social, nacional e mundial vem passando Diante das mudanças que V. $14 \mathrm{~N}^{\mathrm{o}} 2$, dezembro, 2016 
vivemos atualmente, diversas são as repercussões na economia e política, gerando deste modo, as mudanças no campo do conhecimento, das ideias e dos valores.

A política surgiu na Grécia, aproximadamente no século VI. Ela não era como é hoje; dizia respeito, exclusivamente à organização das Pólis (cidades). Estas eram cidades-estados, que se autogeriam e que foram pioneiras na democracia. No Brasil a política surgiu para evitar conflitos e permitir que cada indivíduo pudesse expressar sua diferença.

Quando se fala em política, ainda em diversas vezes se relaciona esta a política partidária do cotidiano, o que mostra-se como conceito restrito frente ao complexo entendimento que a mesma assume. Neste sentido, a politica está relacionada diretamente com a vida em sociedade, no sentido de fazer com que cada indivíduo expresse suas diferenças e conflitos sem que isso seja transformado em um caos social, ou seja, refere-se, principalmente ao conjunto de atividades que de alguma maneira são atribuídas ao Estado Moderno, ou que dele emanam seja urbano, público ou civil.

Para Demo (2007), o Estado detém papel relevante na política, muito embora no espaço participativo sua função seja de instrumentalização, jamais de condução. De um modo geral, a política é subdesenvolvida a medida que souber acionar iniciativas mais estruturais, como educação, cidadania, ciência e tecnologia.

As Políticas Públicas na educação, no Brasil, vão além do ambiente escolar. Neste contexto torna-se necessário que as Políticas Públicas sejam construídas sobre princípios que garantam uma educação de qualidade social, direito de todos e dever do Estado, com participação da comunidade escolar, articuladas com um projeto de desenvolvimento social do Estado e dos municípios, com capacidade de qualificar e incluir socialmente.

Deste modo, a política assume papel fundamental no dia-a-dia, pois querendo ou não, gostando ou não, a política é um "elemento" que está intrínseco no meio social. Para tanto a política é feita todos os dias, constantemente sem nos darmos conta que a fazemos. O ser humano por natureza é político, o que prevalece é a vontade do indivíduo, do eu.

Nesta forma, as políticas são programas de ação governamental, representando o encontro de elementos técnicos de administração de recursos e meios públicos com a escolha política de prioridades para uso desses recursos. A formulação da política pública possui como fases o reconhecimento de assuntos, a formulação de problemas, a identificação das necessidades, a fixação de objetivos, a consideração de opções, a intervenção e a avaliação das consequências.

Visto que a Educação Especial parte de uma política pública efetiva de educação inclusiva, a que deve ser gradativa, contínua, sistemática e principalmente planejada com o objetivo de oferecer aos alunos com deficiência uma educação de qualidade que proporcione na prática, na ação docente, na aprendizagem e nas relações intersociais a superação de toda e qualquer dificuldade que se interponha à construção de uma escola democrática. 
A Legislação que atualmente regulamenta a educação no Brasil (Lei de Diretrizes e Bases da Educação Nacional - LDB 9394/96), em consonância com a Constituição Federal de 1988, assegura a Educação Especial como modalidade de ensino oferecida, de preferência, na rede regular. $\mathrm{O}$ artigo 58 da LDB é dedicado ao tratamento das questões relacionadas à Educação Especial; nele é apontada uma nova concepção de Educação Especial atrelada à questão da inclusão.

Desta forma para Pretto (2006), as políticas são programas de ação governamental, representando o encontro de elementos técnicos de administração de recursos e meios públicos com a escolha política de prioridades para uso desses recursos. A formulação da política pública possui como fases o reconhecimento de assuntos, a formulação de problemas, a identificação das necessidades, a fixação de objetivos, a consideração de opções, a intervenção e a avaliação das consequências.

Já na educação, a política mostra-se de grande relevância, vislumbra-se o papel vital que desempenha na sociedade, salientando a conjuntura dividida em classes/sociedade de classes, cujas classes possuem interesses antagônicos através de manifestação da prática social. Sendo, assim, a educação está voltada para o exercício da cidadania em seu sentido mais pleno, em que os cidadãos efetivamente participam das decisões políticas, enquanto sujeito político que enseja uma revisão profunda na relação tradicional entre educação, e a cidadania.

Conhecer as políticas nacionais que fomentam a educação e os aspectos gerais da sociedade torna-se ponto crucial àqueles que atuam ou atuarão junto às atividades de aprendizado e educação. Reconhecer as repercussões da política aos processos de ensino/aprendizado permite aos envolvidos compreensão da conjuntura que tangencia e influencia os possíveis ranços e avanços deste percurso.

Trabalhar com o tema político em cursos de formação de professores, e necessário antes trabalhar a valorização dos profissionais na educação de forma articulada e prioritária, oferecendo melhores condições de trabalho, salários e carreira para que a política seja promissora de uma formação inicial e continuada permitindo a participação ativa dos professores e de suas entidades nos processos de definição de sua formação e nos rumos da educação pública em nosso país. Para que assim a política exige que sejam tratadas, igualmente, todas as bases da educação escolar, visando sua transformação para a construção de uma nova qualidade da educação básica, orientada pelas necessidades sociais da formação dos alunos.

Em vistas disso, a educação pode requerer que criativamente as pessoas imergem-se na realidade do mundo e no jogo da vida, onde se realiza a convivência humana, na qual se assimilam as tradições do passado, valorizam-se visões generosas de mundo, constroem-se sentidos, de vida e se aprende a lidar com a contraditória e conflitiva condição humana sempre aberta para cima e para frente. 
No campo da Educação Especial a política acaba por assumir uma condição de política generalista, não atendendo ou atendendo de forma limitada os anseios dos grupos. Sendo imperiosa a correta identificação da população real e de suas necessidades, quer seja portadora de diferenças restritivas ou não.

O presente artigo apresenta um ensaio teórico suscitando reflexões acerca das políticas públicas educacionais e o uso das tecnologias no cotidiano escolar. O objetivo do ensaio é discutir algumas politicas públicas em consonância ao uso das tecnologias no processo didático dos alunos com deficiência. Assim, apresenta-se nas próximas seções do artigo reflexões acerca das novas tecnologias e o Atendimento Educacional Especializado, e o uso das politicas públicas na formação dos professores acerca das tecnologias.

Sob esta perspectiva salienta-se que a educação está modificando-se constantemente, novas informações, mudanças, conceitos, e ideias estão chegando para conquistar novos espaços e a grande meta de se chegar a uma educação baseada em valores que perpassam os tempos, mas sem deixar de ultrapassar pelas novas tecnologias que aí estão. Neste sentido, as tecnologias têm a possibilidade de serem incorporadas no processo educacional como recursos didáticos ou ferramentas que promovem o processo de ensino; como instrumento diferenciado de avaliação do aluno e como ferramenta de aprendizagem, pois, com determinados programas de computador, por exemplo, o aluno pode não só obter informações, mas também criar, relacionar, inferir, se expressar, em síntese, pode aprender. Elas podem se constituir no próprio conteúdo curricular, estando vinculado o seu uso às diferentes disciplinas escolares, bem como podem ampliar as possibilidades de interação e comunicação entre os membros da comunidade escolar.

Por fim as tecnologias vêm para auxiliar na inserção da nova era de informação e comunicação nas escolas e no trabalho dos professores. É preciso rever atitudes e formas de trabalho, é preciso buscar conhecer e usufruir do que ainda é novo, é tempo de (re) pensar metodologias e traçar novos caminhos.

\section{Novas Tecnologias e o Atendimento Educacional Especializado}

Cabe ressaltar que estamos vivendo um momento de revolução da Informação e da Comunicação, fundamentada em uma nova tecnologia e a um novo modo de viver, pensar, agir e interagir, produzindo um novo modelo social globalizado, identificado mundialmente como sociedade da informação. Assim, no contexto do cenário escolar e da Educação Especial deve ser potencializado novos paradigmas de ensino, adaptação e inclusão para o aluno com deficiência, incorporando o uso das Tecnologias. 
Salienta-se que a educação não pode eximir-se das transformações tecnológicas em que a sociedade vêm passando. Ela deve privilegiar as necessidades atuais diante dos avanços tecnológicos, fatos esses que não podem ser ignorado se o que se pretende é a formação integral das pessoas, dentro dos princípios e valores que promovem a formação para a cidadania e a preparação para a vida.

Frente a este contexto, percebe-se que o vigente contexto educacional demanda reformulações curriculares no contexto do Ensino Médio, bem como na inclusão digital dos alunos em sala de aula. Nesse sentido, o educador especial além de possuir conhecimentos acerca das políticas públicas sobre inclusão e adaptação dos alunos com deficiência, enseja formação especializada para o uso das tecnologias. Uma vez que, as novas tecnologias podem auxiliar o educador no planejamento didático de suas aulas, de forma a promover a participação do aluno. Logo, o educador especial precisa no jogo das especificidades das deficiências de seus alunos, buscar aportes tecnológicos interativos para incluí-los.

Para Sodré (2012), a mutação tecnológica é principalmente um pretexto histórico para se repensar essa rigidez e as formas de dominação que sempre acompanharam a escrita. Por isso, é culturalmente insuficiente a pura e simples “inclusão digital" dos sujeitos presumidamente excluídos se um processo dessa ordem apenas repete, no domínio da eletrônica, a manipulação das classes populares operada por um tipo de alfabetização que entende como avanço educacional a mera inserção do aprendiz no universo da letra, como se esta representasse um fim em si mesma. Considerando em termos estritamente técnicos, o digitalismo eletrônico não constitui um ambiente educacional extraescolar.

Com o avanço da tecnologia, e das pesquisas em informática é preciso preparar profissionais para dominar o potencial educativo que a tecnologia oferece. Nesse sentido, os avanços tecnológicos acabam proporcionando possibilidades de informação e comunicação que vem transformando a maneira de interação de diversos comportamentos e relacionamentos, já que ao mesmo tempo acaba quebrando o paradigma de relacionamento entre indivíduos.

O processo de exclusão há muito tempo existe em nossa sociedade, sua origem não é consequência da era digital. A exclusão perdura por milênios, a sociedade em castas já determinava os excluídos sociais. A Política Nacional de Educação Especial na perspectiva da Educação Inclusiva (BRASIL, 2008, p.1) "conjuga igualdade e diferença como valores indissociáveis, e avança na ideia da equidade formal ao contextualizar as circunstâncias históricas da produção da exclusão dentro e fora da escola".

Pimentel (2012) as novas tecnologias não são a solução para todos os problemas existentes na sociedade, mas elas têm potencial integralizador e delas dependem os cidadãos que estão excluídos. 
Não se trata de acabar com a exclusão, processo que sempre existirá em uma sociedade capitalista, mas de tentar diminuir os excluídos, não apenas da exclusão atual, mas de todo o contexto em que eles estão inseridos, contribuindo para o estabelecimento da sua cidadania plena, com direitos e deveres respeitados e condições de fomentar a inclusão de outros; e não apenas de tornar-se menos um excluído.

Deste modo, as novas tecnologias direcionadas ao Atendimento Educacional Especializado (AEE), tornaram-se um elemento imprescindível para a implementação de um sistema educacional inclusivo, pois possibilita o acesso às informações, acesso aos conteúdos curriculares, bem como a organização diferenciada das atividades de forma a atender as condições e características do aluno, ou seja, às suas especificidades.

As Tecnologias Assistivas, a Comunicação Alternativa e Ampliada mostra-se atreladas ao desenvolvimento de ações que podem oportunizar autonomia, acesso à informação, integração ao grupo social, dentre outros aspectos que podem favorecer ao processo de ensinoaprendizagem, e assim, o desenvolvimento educacional e social. Desse modo, vão plenamente ao encontro aos objetivos principais do AEE, configurando-se como instrumentos fundamentais para o trabalho realizado nesta área (ROCHA; PLETSCH, 2013).

\section{Políticas Públicas e a formação de professores no uso das Tecnologias}

Na sociedade contemporânea novos conceitos, valores, saberes e relações se estabelecem e começam a emergir a partir da presença das Tecnologias. Essas transformações estão gestando uma nova razão que, em princípio, é incompatível com o atual sistema educacional que permanece fechado, linear, e que vem sendo questionado interna e externamente à escola. Aliado a isso, a chamada globalização tem introduzido significativos desafios para a educação e para todo o sistema educacional em função das possibilidades de articulação que são oferecidas pelos meios tecnológicos de informação e comunicação.

Acerca das políticas públicas que tratam da formação de professores para o uso das tecnologias na educação escolar, reflete-se que são políticas de implementação de recursos tecnológicos na escola e a formação docente para o uso de tais tecnologias, mostram-se resultantes dos interesses dominantes, afastando o uso crítico das tecnologias na formação intelectual dos sujeitos. O sistema capitalista subsidiado por políticas que colocam as tecnologias a seu serviço possui objetivos bem claros. De tal modo, devemos ponderar todos os aspectos que circundam a relação entre as tecnologias e as políticas.

As politicas públicas para Ahlert (2007) são aquelas que democratizam a ciência e a tecnologia requerendo a garantia nas escolas ao acesso às tecnologias da informação e do conhecimento e a formação continuada dos profissionais em educação, alavancada por uma gestão 
democrática que também garanta as transformações necessárias na matriz curriculares, que orientam o processo do ensino e aprendizagem nas escolas.

A inserção das tecnologias no contexto escolar traz desafios aos professores, uma vez que estes acabam por se tornarem os responsáveis pelas implicações que as tecnologias trazem no processo ensino-aprendizagem. Contudo, para além da importância de refletirmos sobre o desafio de preparar os professores para o uso das tecnologias em seu fazer pedagógico, é necessário avaliarmos se a formação contempla as tecnologias por uma ótica crítica, levando os professores a compreenderem que aquilo que o discurso hegemônico proclama, ou seja, as tecnologias como panacéia educativa, bem como a sua utilização sem princípios críticos e éticos, corresponde exatamente ao que o sistema capitalista almeja.

Em sua formação acerca das tecnologias é necessário fornecer aos professores momentos e condições para realizar uma reflexão sobre essa nova prática, ou seja, desenvolver suas competências e habilidades técnicas e proporcionar a eles o entendimento da importância de aliar a teoria com a prática e que possam, deste modo, entender que ambas são complementares, uma não deve se sobrepor a outra.

Para Pereira (2011), em sua formação acerca das tecnologias é necessário fornecer aos professores momentos e condições para realizar uma reflexão sobre essa nova prática, ou seja, desenvolver suas competências e habilidades técnicas e proporcionar a eles o entendimento da importância de aliar a teoria com a prática e que possam, deste modo, entender que ambas são complementares, uma não deve se sobrepor a outra.

A tendência atual das políticas públicas e, consequentemente da construção de um projeto de educação que atenda as necessidades e as especificidades locais é caminhar para a descentralização, atribuindo-se à escola maior poder de decisão, embora nem sempre acompanhado das condições necessárias para o exercício dessa autonomia, conferindo-lhe ao mesmo tempo a responsabilidade pelos resultados finais, ou seja, sucesso e fracasso escolar.

\section{DISCUSSÃO}

Às tecnologias é atribuído o poder de mudar significativa e positivamente o processo de ensino e aprendizagem. De fato, não devemos ignorar as novas tecnologias como possibilidade formativa, contudo, também não podemos entendê-las ingenuamente como possibilidade de resolução de todos os problemas educacionais, já que as tecnologias são utilizadas como instrumentos para propagação dos ideais do mercado.

Para tanto o uso das tecnologias na formação dos professores tem ajudado a pensar uma concepção teórica sobre o uso destas, e em especial o computador na educação, como possibilidade 
de construção de conhecimento, meio de motivação, negando a visão de instrumento de memorização de conteúdos e de avaliação de aprendizagem.

$\mathrm{Na}$ formação de professores as políticas públicas têm se constituído em qualificação e conquista de espaços sociais na busca da construção de novos conhecimentos. As adesões desses novos valores podem facilitar a redução das margens de ambiguidade que afetam a profissão do professor e contribuem para que estes voltem a sentir-se bem.

Em relação ao uso das tecnologias no Atendimento Educacional Especializado, percebe-se que alguns profissionais não estão habilitados há utilizar os recursos de tecnologia. Isso de alguma forma acaba prejudicando ou mesmo impedindo o desenvolvimento dos alunos que dependem, muitas vezes, dessas ferramentas tecnológicas para terem acesso ao currículo e participarem das atividades propostas em sala de aula. Diante, dessa perspectiva, se faz necessário dar aos alunos com deficiência a possibilidade da comunicação, o acesso a conteúdos e a construção de novos conhecimentos, devendo implementar nas escolas os serviços da tecnologia que busque identificar e disponibilizar aos alunos os recursos necessários ao desenvolvimento da autonomia no uso do computador.

Por sua vez, as politicas requerem ser construídas sobre os princípios que garantam uma educação de qualidade social, direito de todos e dever do Estado, com participação da comunidade escolar, articuladas com um projeto de desenvolvimento social do Estado e dos municípios, com capacidade de qualificar e incluir socialmente.

Assim, as novas tecnologias, seja de comunicação ou informação, estão presentes em nosso dia-a-dia não apenas como suporte técnico, mas, principalmente como cultura. È observável que as tecnologias ampliam nossa visão de mundo, transformam as linguagens e propõem novos modelos éticos e novas formas de apreender a realidade. Deste modo, a escola, seus gestores e professores, devem discutir e compreender seu papel nos processos de ensino e aprendizagem.

Neste ínterim, o uso das tecnologias enriquece o processo de ensino-aprendizagem desde que utilizados de forma adequada, de modo contextualizado, para que tenha incidência sobre a aprendizagem dos alunos.

No entanto, o ambiente escolar é compreendido como um lugar de socialização, de aprendizagem, onde distintas crianças se encontram para conviver com suas culturas, distintas características, ampliando sua rede de relações iniciada na família. Sua função, contudo, não se restringe à socialização, mas também a escolarização de todos os alunos nela matriculados, incluindo aqueles com deficiência.

Sabe-se que educação implica refletir sobre sua importância e necessidade iminente para vivermos com plenitude como pessoa e como cidadão envolvido na sociedade. No entanto, o paradigma educacional atual requer políticas educacionais que atendam aos anseios exigidos nas 
diversas áreas da educação, com ênfase ao essencial de toda a educação, o ser humano. Nesse contexto, a implementação das políticas públicas de educação inclusiva no âmbito educacional é relevante, pois contribui efetivamente com uma educação que fará a diferença. Portanto, cabe ressaltar que não é suficiente a constituição de uma política pública educacional bem definida, com conteúdo bem construído, formulado; o importante e imprescindível é trabalhar para que a política aconteça, contemplando de forma efetiva o processo de desenvolvimento e aprendizagem do principal sujeito da esfera educacional: o aluno.

\section{CONSIDERAÇÕES FINAIS}

Pondera-se a necessidade de nos apropriarmos das tecnologias para podermos, por meio delas, nos comunicar, relacionar, informar e aprender. Não podemos mais conviver sem elas, o mundo virtual é necessário ao nosso cotidiano, à vida moderna delas depende, e o domínio sobre elas é urgente. A geração digital, do instantâneo, do agora, do on-line é que comanda a sociedade atual. Não estar em consonância com o uso das tecnologias, determina o excluído do século XXI.

Nesta perspectiva, é preciso enfatizar que o problema não reside nas tecnologias, mas na forma como essas são utilizadas e a quem os seus produtos estão servindo. É aí, que ressaltamos o papel da educação escolar. Se houver claro um norte de formação crítica, haverá necessariamente uma prática pedagógica que viabiliza uma reflexão sobre as tecnologias em todos os aspectos positivos e negativos e que assim, trabalha no sentido da formação intelectual do sujeito.

O uso das tecnologias trouxe grande impacto sobre a educação desenvolvida nos dias atuais, criando novas formas de aprendizado, disseminação do conhecimento e, especialmente, novas relações entre educador e aluno. Esta inserção na educação surgiu da necessidade de conscientizar o povo para a realidade, partindo do pressuposto de que, quanto mais conhecimento a pessoa tiver, maior será sua capacidade de criticar o mundo e as coisas que estiverem ao seu redor.

Nesse sentido, a escola deveria, antes de inserir as tecnologias no processo de ensino e aprendizagem, analisá-las criticamente compreendendo assim, as relações entre os recursos tecnológicos e os mecanismos subjacentes à manipulação, conformação e deformação os sujeitos. A partir daí, é possível desfazer o caráter superficial, efêmero e alienante da formação atual e colocar as tecnologias a serviço de uma educação, de fato emancipatória e que trabalha a resistência perante o mercado e a ideologia dominante.

Portanto, a inserção das novas tecnologias na educação está transformando o ambiente escolar e criando novas formas de aprendizagem. Por isso, é importante que o educador compreenda o uso da tecnologia de maneira ampla, assumindo uma postura multidisciplinar de integração de 
conteúdos e das disciplinas, ampliando a abrangência do conhecimento que pode ser adquirido pelo aluno.

Com isso, esperamos o surgimento de outras políticas na perspectiva inclusiva, reformas e propostas que possam ser discutidas, aprofundadas, reinventadas e de preferência bem sucedidas no cenário educacional especial inclusivo, pois as discussões não se limitam neste texto que pretende instigar novas leituras, análises, considerações e atitudes favoráveis a uma política de educação para todos sem estigmas, discriminação e segregação.

\section{REFERÊNCIAS}

AHLERT, Alvori. Políticas Educacionais para uma democratização do acesso à ciência e a tecnologia. Revista Athenea Digital,n.12,p.25-37,out 2007.Disponível em: <https://dialnet.unirioja.es/descarga/articulo/2469469.pdf>. Acesso : 10 jun. 2016.

BRASIL. Lei de Diretrizes e Bases da Educação Nacional (Lei no 9394/96). Brasília, 1996.

BRASIL. Ministério da Educação. Secretaria de Educação Especial. Política Nacional de Educação Especial na perspectiva da Educação Inclusiva. Brasília: MEC/SEESP, 2008. Disponível em: 〈http://www.portal.mec.gov.br〉. Acesso em: 10 nov. 2016.

DEMO, Pedro. Política Social, educação e cidadania. 10. ed. Campinas, SP: Papirus, 2007.

PEREIRA, Rita. de Cássia. de Sena.Prado. Tecnologias Assitivas e Deficiência: Algumas

Considerações. Revista Educação, Tempo,Digitalização.V.13, n.1,p.119-133,jul/dez .2011.

PIMENTEL, Nara Maria. As Políticas Públicas para a Tecnologia da Informação e da Comunicação e Educação a Distância no Brasil. Revista Educação em Foco, Juiz de Fora, n.2,p81-102, jun./out 2012. Disponível em: < http://www.ufjf.br/revistaedufoco/files/2013/05/artigo4.pdf >.Acesso : 22 jun. 2016.

PRETTO, Nelson de Lucca. Políticas Públicas Educacionais no mundo Contemporâneo. Revista Liinc, Rio de Janeiro, n.1,p.8-21,mar.2006.Disponível em : < http://liinc.revista.ibict.br/index.php/liinc/article/view/201/116>. Acesso : 08 maio. 2016.

SODRÉ, Muniz. Reinventando a educação: diversidade, descolonização e redes. Petrópolis, RJ: Vozes, 2012. 